\title{
Development strategies for small and medium-sized enterprises with limited investment resources
}

\author{
Boris Gusakov ${ }^{1}$, and Anna Sotnikova ${ }^{2}$ \\ ${ }^{1}$ Belarusian National Technical University, Minsk, Republic of Belarus \\ ${ }^{2}$ Belarusian National Technical University, Minsk, Republic of Belarus
}

\begin{abstract}
The main source of investment resources for small and medium-sized enterprises is their own profit. The dynamic development of these enterprises is possible only with a strategic program aimed at implementing independent discrete measures. The following tasks are relevant: development of a set of program measures; optimization of measures; maintenance of the financial stability of the enterprise by adjusting development program indicators. The indicators are strategic guidelines for the development. The target functions of the effectiveness of strategic management are minimization of the period of implementation of the development program and the maximum asset growth rate. To assess the effectiveness of development, the following indicators developed by the authors can be used: the coefficient of innovation management, which characterizes the average geometric growth rate of assets attracted during the initial period; the index of innovation management, which characterizes the quality of management by comparing the average geometric growth rate of assets of the optimal and basic variants of the development program.
\end{abstract}

\section{Introduction}

Sustainable social and economic development of the country depends on small and medium-sized enterprises. This sector is quite mobile, easily adapts to frequently changing market conditions, and ensures socio-economic stability through the creation of new jobs. The National Strategy for Sustainable SocioEconomic Development of the Republic of Belarus assumes an increase in the contribution of small and medium-sized enterprises to GDP from $21.6 \%$ in 2019 to $50 \%$ in 2030 .

The problem that hinders the development of small and medium-sized enterprises is the lack of investment resources. Small and medium-sized enterprises do not have liquid capital or it is not sufficient to obtain a bank loan. The absence of a state system for ensuring loans hinders entrepreneurial activities. The main source of investment for small and medium-sized enterprises in the start-up period is contributions of founders, and profit is used for development in the foreseeable future.

In the post-Soviet space, the traditional definition of the concept of profit is widely used: "Profit is the difference between income and costs". This definition helps to calculate profit, reveals the main properties and relationships of profit. This is a quasi or fake concept.

\section{Materials and methods}

The main properties of profit were defined by K. Marx: "a certain amount of value is put into circulation in order to extract a large amount of value from it." It is an excess surplus value" [1, p. 45]. Marx emphasized that profit is an integral part of the surplus value. In a letter to Engels of April 30, 1868, Marx wrote: "Profit is just another name or another category for the surplus value" [2, p. 145]. Marx indicated the possibility of using profit as part of the surplus value for the development of entrepreneurship. He argued "that accumulation, transformation of the surplus value into capital is a process of reproduction on an expanded scale, regardless of whether such expansion is expressed extensively, by building new factories in addition to the old ones, or intensively, by increasing the scale of production" [1, Ch. 22]. The provisions form the basis for the general and specific concepts of profit.

The general definition of profit reveals its main properties. It performs an indicative function. When developing the concept, it was taken into account that the owners can use assets for the production and provision of services, place financial assets on a deposit, or purchase shares of enterprises. In all cases, the owners will make a profit.

"Profit is an increase in the value of assets when they are used in entrepreneurial activities under the agreement."

Specific concepts of profit repeat its basic properties and show its connections based on the

\footnotetext{
Corresponding author: b-99@yandex.ru
} 
specifics of entrepreneurial activity. They perform an informational function and show directions of the drive for making and using profits.

Profit is an increase in the value of company's assets due to current, investment and financial activities (except for an increase in obligations to creditors and contributions of founders), directed to payments to the budget, accumulation, expanded reproduction, consumption and other needs permitted by law [3, p. 93].

The concept reveals the main properties and connections of profit with its sources. The concept is based on the provisions of Karl Marx's theory and requirements of the current legislation. When optimizing the value of profit received, the owners should focus on the possibility of choosing a rational direction for the use of assets. When rationalizing the use of profit, the criterion of allocative efficiency is used - the profit is directed to those objects or to encourage those members of society who provide additional profitability of the assets. Objects can be short-term or long-term assets, and members of society are employees and managers of the organization, as well as consumers of the products and services. The government provides tax incentives to encourage the development of the organization; owners and managers change the proportions of profit distribution when the economic situation changes, the financial stability of the organization and changes in the social needs.

\section{Results and discussion}

A set of factors reflecting the properties and relationships of profit are used in the development of a model for the strategic development of small and medium-sized enterprises. The model includes three parts: selection of a development strategy and proportions of distribution and use of profits; development and optimization of the development program; monitoring of parameters of the development program. The strategic development model is shown in Figure 1.

There are three variants of the strategy: stable development, accelerated development; survival. The choice depends on the potential of an enterprise. The strategic potential is assessed by an integral indicator calculated by eighteen standard technical and economic factors available in open statistical reporting [4]. Standard indicators are combined into three aggregates: financial and economic (asset liquidity); market (indicators characterizing the market share of the enterprise); labor and material and technical (quality of life and materialized labor). For each standard indicator, the indicator of prospects for the i-th factor is calculated, and the specific indicators of prospects are integrated with the organization's potential by formula (1):

$$
I_{\mathrm{CP}}=\frac{\sum D_{i}}{i}=\frac{\sum k_{i x} / k_{i \mathrm{M}}}{i}(1)
$$

where $I_{d s}-$ the organization's potential for choosing a development strategy;
$D i$ - indicator of the organization's potential by the i-th factor;

$i-$ number of potential's indicators.

$k_{i x}-$ the i-th standard indicator;

$k_{i \mathrm{M}}$ - the maximum value of the i-th standard indicator in the sample represented by enterprises with a development rate higher than the industry average.

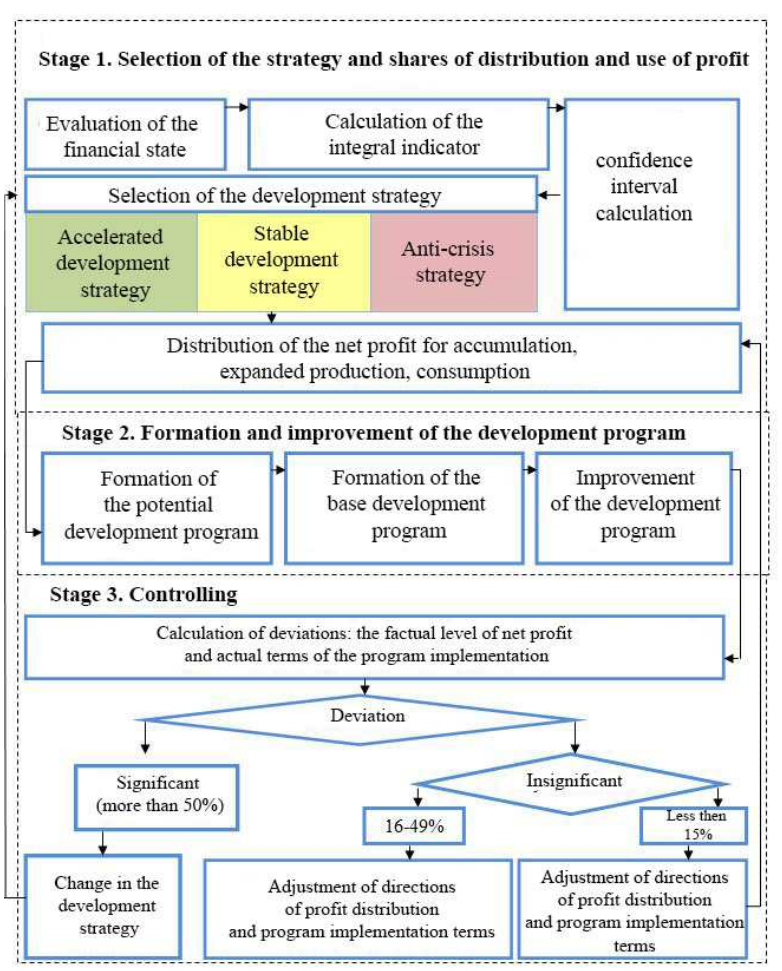

Figure 1. The model of strategic development

The integral indicator of the organization's potential is a positive value; its maximum value is equal to 1 . The minimum indicator of 0.1 was obtained empirically from the analysis of calculations using five samples of small and medium-sized enterprises of various profiles.

The ranges of admissible values of the organization's potential for strategies of accelerated development, stable development, survival and their qualitative characteristics were determined.

The range of permissible values of the integral indicator for strategically stable development is defined as the average of the values of the integral indicator of a representative sample. It was revealed that small and medium-sized enterprises with a potential in the range of the confidence interval having a development rate close to the industry average, rarely experience financial difficulties, have a development rate close to the industry average. Accordingly, large values of the organization's potential correspond to the strategy of accelerated development, lower values of the indicator determine the strategy of survival. A qualitative analysis of specific indicators of small and mediumsized enterprises made it possible to identify their basic characteristics.

The accelerated development strategy is recommended for enterprises that have potential in the upper range, which corresponds to the presence of 
significant own financial resources. They are able to attract loans. These enterprises are encouraged to grow their assets above the industry average. The sustainable development strategy is suitable for enterprises with limited investment resources, stable levels of production volumes and financial stability indicators close to the industry average. The survival strategy is recommended for enterprises with unsatisfactory indicators of financial stability.

When choosing a strategy for stable or accelerated development, the strategic development program for a small or medium-sized enterprise is developed. It involves the implementation of the first measure at the expense of own investment resources and subsequent independent measures. Financial resources of the depreciation fund reproduce the value of worn-out assets, and the profit increases enterprise's assets. The speed of implementation of the program depends on the ability of entrepreneurs to use project management methods.

The optimal development program is implemented at several stages.

At the first stage, it is necessary to develop a potential program based on the marketing research and analysis of possible development measures. Using the method of expert assessments, activities that cannot be implemented are eliminated from the potential program even in the strategic period of 5-10 years.

At the second stage, the basic program is developed. An individual business plan is developed for each measure.

At the third stage, priorities of the measures are determined. The first (highest) priority is technological. It determines the priority of measures required for the development of the enterprise. For example, when creating a roadside complex, the gas station has a technological priority.

The second priority is given to the measures with a short return on investment, allowing for the quick accumulation of financial resources for implementing subsequent measures of the development program. The third priority is given to the activities with a long return on investment. The fourth priority determines the need for the simultaneous completion of two or more activities. Infrastructure projects also have this priority. For example, a nuclear power plant is being launched in Belarus, and the power grid is limited in capacity, and potential consumers of electricity are not ready. Simultaneously with the commissioning of the nuclear power plant, it is necessary to ensure the demand for electricity.

At the fourth stage, the first optimization of the development program is carried out. Measures are arranged in a sequence according to their priority. At the same time, the activities united by the priority are arranged in a sequence that allows them to be completed simultaneously as a complex event with a long period of return on investment. The first optimization of the priority of measures of the development program has a significant drawback; it does not take into account the period of accumulation of financial resources for the next event. The first activity is funded at the starting point of implementation, since the initial financial resources for investment activities must be accumulated by the owners. Subsequent activities are funded using the net income from operating facilities and loans $[5,6,7]$.

At the fifth stage, the second optimization of the development program is carried out. The method of combinatorics is used. It includes a sequential rearrangement of the order of implementation of the measures of the second and third priorities. Optimization requires several iterations. After each permutation, the average geometric growth rate of assets is calculated. The optimal variant of the strategic development corresponds to a sequence of activities that ensure the maximum asset growth rate. The growth rate of assets is the coefficient of innovation management based on technical innovations.

Technical innovation is a new or improved product or process created using modern scientific knowledge, with improved technical characteristics and increased added value.

In our case, a new management process ensures a reduction in the period of implementation of the development program and additional added value, since the income received earlier is of great value, it will provide additional income.

The coefficient of innovation management is determined by formula (2):

$$
I M R R=\sqrt[T]{\frac{\text { Cash }+\sum_{i=0}^{n} P_{i}}{P V I}}-1,
$$

where IMRR is the innovation management ratio;

$T$ is the term of implementation of the development program, years;

Cash is unused funds at the time of completion of the development program secured by the flow of unused net income from previously commissioned objects under the program during the implementation of the last measure, rubles;

$\sum \mathrm{Pi}$ is the market value of objects created, rubles;

$\mathrm{N}$ is the number of objects created, pcs;

$P V I$ - the amount of the owner's discounted investment, rubles.

The dynamics of the value of assets is shown in Figure 2. It differs from the dynamics of the value of assets when implementing a business plan for one object. In our case, there are financial resources, three objects at by market value and cash accumulated during the implementation of the last third measure.

The market value of objects of the development program is determined for the date of its completion by the profitability method. The facilities will be put into operation in order of priority and, accordingly, have different periods of operation. Accordingly, the market value of each object should be determined individually. It consists of the residual value of property and Goodwill. Simplified Goodwill is capitalized economic profit calculated by formula (3):

$$
\mathrm{Pi}=\mathrm{Coi}+\mathrm{Pgi}=\mathrm{Co}+\frac{\mathrm{Pg}}{\frac{1}{t_{\mathrm{g}}}+\mathrm{EK}},
$$


where Pi is the market value of the $\mathrm{i}$-th object as of the date of completion of the development program;

Co is the residual value of the i-th object as of the date of completion of the development program;

$\mathrm{Pg}$ is the cost of goodwill;

$\mathrm{Pg}$ is the economic profit of the object (profit of goodwill);

$t_{\mathrm{g}}$ is the service life of Goodwill, years. The service life of Goodwill is assumed to be 5 years;

Ек is the relative value of the rate of payment for the loan.

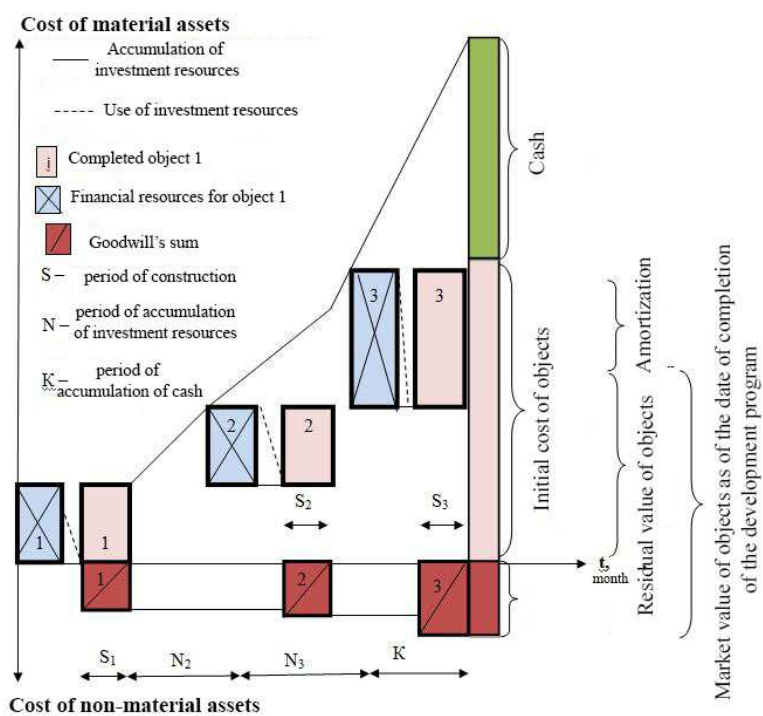

Figure 2. The scheme of implementation of the development program (three objects)

The effectiveness of the development program characterizes the general and specific index of innovation management.

The general index of innovation management shows how many times the growth rate of assets attracted for the development program is higher than the rate of loan payment. The program is effective if the index is more than 1 . The index is calculated according by formula (4):

$$
F L_{g}=\frac{I M R R}{E \kappa},
$$

where $F L_{g}$ is the general index of innovation management;

$I M R R$ is the innovation management coefficient; form.

$E \kappa$ is the rate of payment for the loan in a decimal

The specific index of innovation management characterizes how many times the growth rate of assets in the used version of the development program is higher than in the version with the minimum coefficient of innovation management. It is calculated by formula (5):

$$
F L_{S}=\frac{I M R R i}{\text { IMRRmin }}
$$

where $F L_{s}$ is the specific index of innovation management;

$I M R R_{i}$ is the coefficient of innovation management of the i-th pti $\mathrm{n}$ f the devel pment pr gram;
$I M R R_{\min }$ is the minimum coefficient of innovation management in the development program.

When implementing the development program, after the completion of the next measure, monitoring measures should be implemented. The fulfillment of the strategic plan is checked in terms of time and profit. In case of deviation of the actual level of profit and the actual period of implementation of the next program measure, the following solutions are possible: use of a different development strategy, a differentiated approach to adjusting the profit. If the actual value of net profit decreased as a result of changes in the market conditions, the net profit does not change or decreases while maintaining the distribution proportions. If the actual amount of net profit has decreased as a result of changes in the internal environment, the profit is used in previously set proportions.

\section{Conclusion}

The development strategy developed for small and medium-sized enterprises is an important element of project management. The development and implementation of the strategic program allow us to consider long-term prospects for the development of the enterprise in a formalized form. In addition, it becomes possible to assess the organization's potential at the starting point of the strategy and control the quality of management by comparing current and longterm actual and planned indicators.

The specificity of the strategy for the development of small and medium-sized enterprises is self-financing from own net income. In this case, depreciation compensates for the cost of depreciation of assets, and profit allows you to increase the value of assets used to produce goods and services.

In the modern economy, part of the net profit should be used to encourage managers, workers, employees and customers. In these conditions, an important task is rational management of the size of incentive payments.

In contrast to large enterprises, in small and medium-sized enterprises, the process of development is discrete, it is necessary to choose the sequence of activities. The criterion for the optimal program is the maximum growth rate of assets and the minimum period of implementation of the development program.

The effectiveness of a development strategy is specific for two reasons. Firstly, investments are financed from the income received, and the period of implementation of the development program is optimized.

\section{References}

1. K. Marx, Capital. Criticism of Political Economy. Volume 3. Political literature. (Moscow: Politizdat, 1950)

2. K. Marx, F. Engels, Collection, vol. 32 (Moscow: Political Literature Publishing House, 1955-1974) 
3. B. Gusakov, A. Sotnikova, Bulletin of University, 12, 10-14 (2018)

4. A. Tsarikayev, Business in Law 4, 222-224, (2011)

5. G. Birman, S. Schmida, Economic Analysis of Investment Projects (Banks and Exchanges, YUPITI, 1997)

6. M. Bromwich, Analysis of the economic efficiency of investments (INFRA-M, 1996)

7. B. Gusakov, Chief Economist, 10, 65-73 (2015) 